\title{
Epidemiology of unintentional injury in children admitted to ICU in China mainland: a multi-center cross-sectional study
}

\author{
Jing Ye ${ }^{1} \wedge$, Yiyao Bao ${ }^{1}$, Jicui Zheng ${ }^{2}$, Jianfeng Liang $^{3}$, Lei $\mathrm{Hu}^{1}$, Linhua $\mathrm{Tan}^{1} \wedge$; on behalf of the Pediatric \\ Intensive Care Committee of Chinese Medical Doctor Association Investigators
}

${ }^{1}$ Department of Surgical ICU, The Children's Hospital, Zhejiang University School of Medicine, National Clinical Research Center for Child Health, Hangzhou, China; ${ }^{2}$ Department of Neurosurgery, The Children's Hospital, Fudan University School of Medicine, Shanghai, China; ${ }^{3}$ Department of Medical Statistics, The Children's Hospital, Zhejiang University School of Medicine, National Clinical Research Center for Child Health, Hangzhou, China

Contributions: (I) Conception and design: J Ye, L Tan; (II) Administrative support: Y Bao, L Tan; (III) Provision of study materials or patients: Y Bao, J Zheng, L Hu; (IV) Collection and assembly of data: All authors; (V) Data analysis and interpretation: J Ye, J Liang; (VI) Manuscript writing: All authors; (VII) Final approval of manuscript: All authors.

Correspondence to: Linhua Tan. Department of Surgical ICU, The Children's Hospital, Zhejiang University School of Medicine, No. 3333 Bin-Sheng Road, Bin-Jiang District, Hangzhou 310052, China. Email: chtlh@zju.edu.cn.

Background: To investigate the epidemiology of unintentional injury in children admitted to Intensive Care Unit (ICU) in China mainland.

Methods: A total of 39 hospitals in 19 provinces contributed to the 1-day point prevalence study of serious unintentional injury in children aged 0-16 years admitted to ICU.

Results: A total of 1,017 patients from the 39 participating ICUs on the study day were included. Among them, 56 pediatric patients were identified to be suffered from unintentional injury from 18 participating ICUs, accounting for $5.5 \%(56 / 1,017)$ of all the ICU patients. The percentage of boys was more than twice the percentage of girls. Most patients had an age of less than 6 years old ( $n=42,75 \%)$. The leading cause of unintentional injury was fall $(n=17,30.4 \%)$. The patterns of unintentional injury in children were agerelated. There were no urban-rural differences in our cohort. The injury happened on 12:00-18:00 PM in 27 cases (48.2\%), and 28 patients (50\%) had injuries happened at working day. 35 patients (62.5\%) received primary treatment at local hospitals. Thirty-five patients $(62.5 \%)$ needed resuscitation in the emergency department, 15 patients (26.8\%) still needed resuscitation in ICU. These 56 children suffered from a total of 106 lesions corresponding to 1.89 lesions per patient. Respiratory failure was most commonly seen $(n=18$, $32.1 \%)$. There was no death in our cohort during the study. After effective treatment during their ICU stay, 45 (80.4\%) patients showed improvement, with Glasgow Coma Scale (GCS), Pediatric Trauma Score (PTS) and Pediatric Risk of Mortality III (PRISM III) score significantly better than those before treatment $(\mathrm{P}<0.05)$. Conclusions: Higher injury rates among children under 6 years old of age illustrate the need for preventive measures, especially programs and public policies targeting this high-risk group.

Keywords: Epidemiology; children; intensive care; unintentional injury

Submitted Aug 15, 2021. Accepted for publication Dec 24, 2021.

doi: $10.21037 / \mathrm{tp}-21-387$

View this article at: https://dx.doi.org/10.21037/tp-21-387

^ ORCID: Linhua Tan, 0000-0001-6624-4970; Jing Ye, 0000-0002-2856-2254. 


\section{Introduction}

Unintentional injury is a major public health concern globally, and attributes to the leading cause of mortality and morbidity in children. It is reported that about 875,000 children under the age of 18 years died as a result of injury or violence in 2002 (1). Data from the China National Disease Surveillance System show that accidental injuries have become the number one cause of death in the 1-14 age groups. The incidence rate of unintentional injuries in children increases rapidly at about $7-10 \%$ per year (2).

Studies on investigating child injuries worldwide have been conducted over the past few decades $(3,4)$. Because of the vulnerability of children, accidental injuries accounted for $13 \%$ of all disability-adjusted life years globally and for $4.9 \%$ among children aged 4 to 14 years in the United Kingdom (5). Most of the epidemiological studies of injuryrelated child deaths that have been conducted in China are limited to single central data $(6,7)$. However, serious unintentional injury in children has received little or no attention, especially in the context of China nationwide.

In this study, we conducted a multicenter 1-day point cross-sectional survey in the pediatric Intensive Care Unit (ICU) in China mainland. We aimed to investigate the epidemiology of serious unintentional injuries in children aged $0-16$ years who were admitted to ICU in China mainland. The significance of this study and other information may help guide prevention strategies aimed at reducing the incidence of accidental injuries among children in China mainland. We present the following article in accordance with the STROBE reporting checklist (available at https://tp.amegroups.com/article/ view/10.21037/tp-21-387/rc).

\section{Methods}

\section{Definition of unintentional injury}

Injury is defined as physical damage caused by external causes (intentional or unintentional). An unintentional injury is defined as "an unexpected, unintentional and violent event, affecting a child, with or without detectable lesions, and subsequently leading to medical attention" (3).

\section{Pediatric ICU (PICU) network}

A total of 39 hospitals in 19 provinces across the country participated in this survey. Collaborative research group from 20 children's hospitals and 19 general hospitals, all in either municipalities $(n=8)$, provincial cities $(n=17)$ or the other cities $(n=14)$ serving as regional tertiary medical/pediatric centers. Thirty-six hospitals are tertiary hospitals level A. Three hospitals are tertiary hospitals level B. Twenty-six hospitals are affiliated with university. 34 hospitals have independent PICUs (Appendix 1). The Children's Hospital, Zhejiang University School of Medicine served as a coordinating center.

\section{Inclusion criteria and study design}

A total of 39 hospitals in 19 provinces in China mainland contributed to the 1-day point prevalence study of serious unintentional injury admitted to ICU in children aged $0-16$ years in China mainland. A contact doctor from each participating hospital who is responsible for collecting and filling out the unified electronic form of the children who meet the standards on the survey day, sending it back to the Children's Hospital of Zhejiang University.

Data was collected from 0:00 to 24:00 on February 1, 2019. All pediatric patients presented in participating ICUs on the study day were included. Among them, the patients with the diagnosis of unintentional injury were analyzed in detail. Data on patient demographics, external causes of injury codes [International Classification of Diseases (ICD10)] categories of unintentional injuries, clinical manifestations, severity of illness, clinical treatment and outcomes were collected and analyzed.

\section{Human rights}

All procedures performed in this study was in accordance with the Declaration of Helsinki (as revised in 2013). The institutional ethics committee at The Children's Hospital, Zhejiang University School of Medicine approved this observational study with minimal risk and no informed consent required (No. 2017-IRB-042). The ethical agreement was adopted by each participating hospital.

\section{Statistical analysis}

Continuous variables with skewed distribution are displayed by using medians [interquartile range (IQR)] and categorical variables by using as number of cases and percentage. Kolmogorov-Smirnov test or Wilcoxon rank sum test (continuous variables) and Pearson $\chi^{2}$ test (categorical variables) were used to compare the difference between subgroups of patients. Statistical significance was 


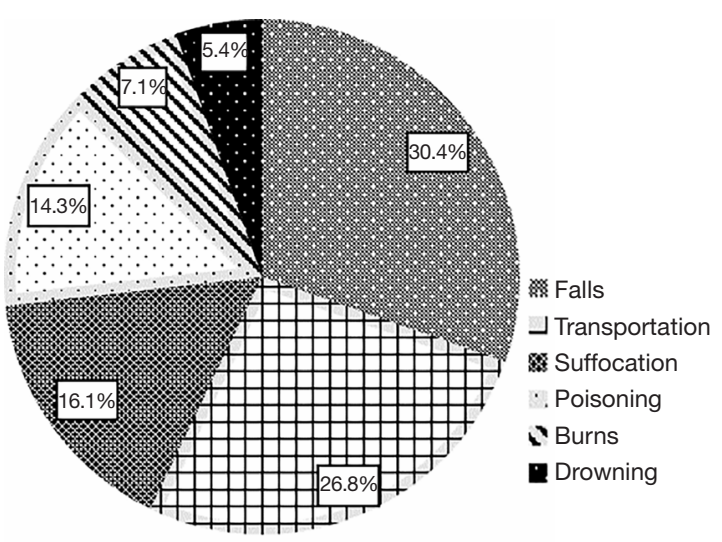

Figure 1 Category of unintentional injury in children admitted to Intensive Care Unit.

Table 1 Characteristics of the study cohort $(\mathrm{n}=56)$

\begin{tabular}{|c|c|}
\hline Characteristics & Study patients $(n=56)$ \\
\hline Age $(y)$ & $3.6(1.0-6.7)$ \\
\hline Male, n (\%) & $39(69.6)$ \\
\hline Weight (kg) & $15.0(10.6-21.8)$ \\
\hline Days after injury during survey (d) & $2.5(1.0-9.0)$ \\
\hline \multicolumn{2}{|l|}{ Category of injury, n (\%) } \\
\hline Falls & $17(30.4)$ \\
\hline Transportation & $15(26.8)$ \\
\hline Suffocation & $9(16.1)$ \\
\hline Poisoning & $8(14.3)$ \\
\hline Burns & $4(7.1)$ \\
\hline Drowning & $3(5.4)$ \\
\hline \multicolumn{2}{|l|}{ Body region of injury lesions, $\mathrm{n}(\%)$} \\
\hline Thorax & $36(64.3)$ \\
\hline Head & $28(50.0)$ \\
\hline Abdomen & $13(23.2)$ \\
\hline Extremities & $10(17.9)$ \\
\hline Pelvis & $6(10.7)$ \\
\hline Peripheral nerve & $5(8.9)$ \\
\hline Spinal & $4(7.1)$ \\
\hline Heart & $4(7.1)$ \\
\hline
\end{tabular}

Categorical data are presented as $\mathrm{n}(\%)$. Continuous data are presented as median (interquartile range). considered at a two-sided 5\% level. All statistical analyses were conducted with SPSS Statistics ${ }^{\circledR}$ software package (Version 23, IBM Inc., Armonk, NY, USA).

\section{Results}

\section{Characteristics of serious unintentional injuries in children in China Mainland}

From 0:00 to 24:00 on February 1, 2019, a total of 1017 patients from the 39 participating ICUs in China mainland on the study day were included in this study. Eighteen of the participating 39 hospitals reported a total of 56 patients admitted to ICU because of serious unintended injury, and the other 21 hospitals reported no relevant cases. These 18 hospitals are all tertiary hospitals level A children's hospitals with independent PICU, 13 of which are children's hospitals affiliated with university (Appendix 1). The percentage of unintentional injury accounts for $5.5 \%(56 / 1,017)$ of all the ICU patients.

Among these 56 pediatric patients, 69.6\% (39/56) were males and $30.4 \%$ (17/56) were females. The percentage of boys was more than twice the percentage of girls. They had a median age of 3.6 years (IQR, 1.0-6.7 years), and a median body weight of $15.0 \mathrm{~kg}$ (IQR, 10.6-21.8 kg). The leading cause of unintentional injury was fall $(\mathrm{n}=17,30.4 \%)$, followed by transportation injury $(\mathrm{n}=15,26.8 \%)$, suffocation $(\mathrm{n}=9,16.1 \%)$, poisoning $(\mathrm{n}=8,14.3 \%)$, burns $(\mathrm{n}=4,7.1 \%)$ and drowning (n=3,5.4\%) (Figure 1, Table 1).

Children were dividing into the following groups by age: less than $1,1-6,6-12$, and $12-16$ years. The types of unintentional injury varied substantially with age. Most patients who suffered from unintentional injuries had an age of less than 6 years old $(n=42,75 \%)$. The most common cause of unintended injuries in children younger than $1 \mathrm{y}$ were suffocation $(\mathrm{n}=6,37.5 \%)$, whereas falls $(n=10,38.5 \%)$ and transportation injury $(n=7,26.9 \%)$ were commonly seen in preschool children with an age of 1-6 years (Table 2).

Among these 56 children with unintentional injuries, 20 $(35.7 \%)$ cases lived in a rural area, $20(35.7 \%)$ children lived in urban-rural fringe area, and $16(28.6 \%)$ children lived in urban area (Table 2). The injury happened on 12:00-18:00 $\mathrm{PM}$ in 27 cases (48.2\%), and 28 patients (50\%) had injuries happened at working day.

These 56 children suffered from a total of 106 lesions 
Table 2 The epidemiology of serious unintentional injuries in children aged $0-16$ years in China

\begin{tabular}{|c|c|c|c|c|c|c|c|}
\hline Type of injury & Total injuries & Falls & Transportation & Poisoning & Suffocation & Drowning & Burns \\
\hline Male & 39 (69.6) & 13 (33.3) & $8(20.5)$ & $5(12.8)$ & $6(15.4)$ & $3(7.7)$ & $4(10.3)$ \\
\hline Female & $17(30.4)$ & $4(23.5)$ & 7 (41.2) & $3(17.6)$ & $3(17.6)$ & $0(0)$ & $0(0)$ \\
\hline \multicolumn{8}{|l|}{ Age group, n (\%) } \\
\hline $1-6$ years & $26(46.4)$ & $10(38.5)$ & 7 (26.9) & $4(15.4)$ & $3(11.5)$ & $1(3.8)$ & $1(3.8)$ \\
\hline $6-12$ years & $10(17.9)$ & $2(20.0)$ & $3(30.0)$ & $3(30.0)$ & $0(0)$ & $1(10.0)$ & $1(10.0)$ \\
\hline $12-16$ years & $4(7.1)$ & $1(25.0)$ & $2(50.0)$ & $1(25.0)$ & $0(0)$ & $0(0)$ & $0(0)$ \\
\hline \multicolumn{8}{|l|}{ Site of injury, n (\%) } \\
\hline Village & $20(35.7)$ & $4(20.0)$ & $5(25.0)$ & $5(25.0)$ & $4(20.0)$ & $1(5.0)$ & $1(5.0)$ \\
\hline
\end{tabular}

Categorical data are presented as $\mathrm{n}(\%)$.

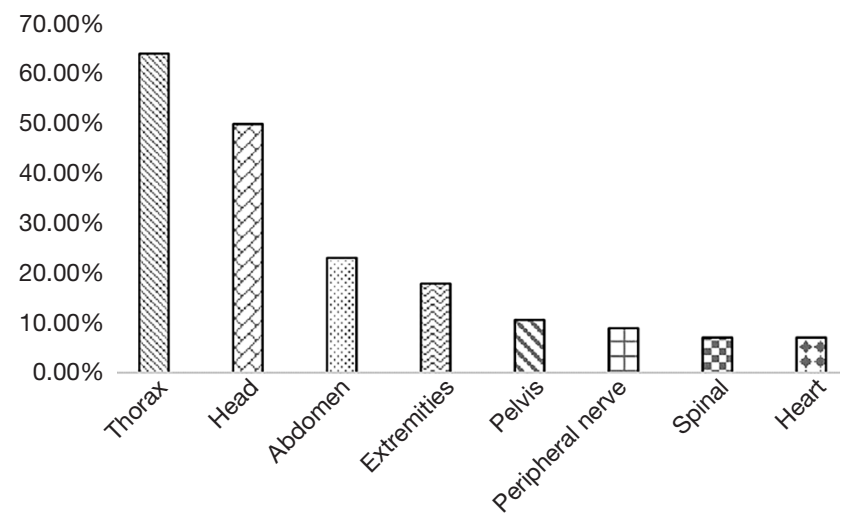

Figure 2 Body region of unintentional injury in children admitted to Intensive Care Unit.

corresponding to 1.89 lesions per patient. The majority of lesions were to the thorax (64.3\%), head (50.0\%), abdomen (23.2\%) and extremities (17.9\%) (Figure 2). Many children had major complications when they admit to the ICU. Respiratory failure was most commonly seen $(\mathrm{n}=18,32.1 \%)$, followed by shock ( $\mathrm{n}=13,23.2 \%)$, metabolic acidosis $(\mathrm{n}=13$, $23.2 \%)$, and acute traumatic coagulopathy $(\mathrm{n}=6,10.7 \%)$. Other complications included multiple organ failure $(\mathrm{n}=3$, $5.4 \%)$ and hypothermia $<35^{\circ} \mathrm{C}(\mathrm{n}=2,3.6 \%)$ (Table 3).

The median score of Pediatric Risk of Mortality III (PRISM III), Glasgow Coma Scale (GCS) and Pediatric Trauma Score (PTS), on admission to ICU was 6.0 (IQR,
2.0-12.0), 13.0 (IQR, 7.0-15.0), and 7.5 (IQR, 5.0-9.0) respectively (Table 4).

\section{Treatment and outcomes}

Thirty-five patients $(62.5 \%)$ received primary treatment at local hospitals. Thirty-five patients $(62.5 \%)$ needed resuscitation in the emergency department, 15 patients $(26.8 \%)$ still needed resuscitation in ICU. Twenty-eight (50\%) patients received fluid resuscitation, $13(23.2 \%)$ patients underwent tracheal intubation, $3(5.4 \%)$ patients underwent cardiopulmonary resuscitation and $2(3.6 \%)$ patients underwent massive transfusion (Table 3).

After effective treatment during their ICU stay, 45 (80.4\%) patients showed improvement, with GCS, PTS and PRISM III score significantly better than those before treatment $(\mathrm{P}<0.05)$. The median score of PRISM III, PTS and GCS on the survey day was 3.0 (IQR, 0.0-7.5), 9.0 (IQR, 7.0-10.0) and 15.0 (IQR, 10.0-15.0), respectively (Table 4). There were no deaths in our cohort during the survey.

\section{Discussion}

This is a national, multi-center, observational study aiming to investigate the epidemiology of serious unintentional injury in children admitted to ICU from different 
Table 3 Treatment and outcome of the 56 patients with serious unintentional injuries

\begin{tabular}{|c|c|c|}
\hline Treatment and outcome & $\begin{array}{l}\text { Cases } \\
(\mathrm{n})\end{array}$ & $\begin{array}{c}\text { Percentage (\%) or M } \\
\text { (P25-P75) }\end{array}$ \\
\hline \multicolumn{3}{|l|}{ Location receiving resuscitation } \\
\hline On-site & 6 & 10.7 \\
\hline Emergency room & 35 & 62.5 \\
\hline ICU & 15 & 26.8 \\
\hline \multicolumn{3}{|l|}{ Type of resuscitation } \\
\hline Fluid resuscitation & 28 & 50.0 \\
\hline Tracheal intubation & 13 & 23.2 \\
\hline Cardiopulmonary resuscitation & 3 & 5.4 \\
\hline Massive transfusion & 2 & 3.6 \\
\hline \multicolumn{3}{|l|}{ Primary treatment in local hospital } \\
\hline Yes & 35 & 62.5 \\
\hline No & 21 & 37.5 \\
\hline \multicolumn{3}{|l|}{ Surgery in local hospital } \\
\hline Yes & 2 & 3.6 \\
\hline No & 54 & 96.4 \\
\hline \multicolumn{3}{|l|}{ Treatment in participating hospital } \\
\hline Emergent surgery & 9 & 16.0 \\
\hline Elective surgery & 4 & 7.1 \\
\hline Mechanical ventilation & 20 & 35.7 \\
\hline \multicolumn{3}{|l|}{ Complications on ICU admission } \\
\hline Respiratory failure & 18 & 32.1 \\
\hline Shock & 13 & 23.2 \\
\hline Metabolic acidosis & 13 & 23.2 \\
\hline Acute traumatic coagulopathy & 6 & 10.7 \\
\hline Multiple organ failure & 3 & 5.4 \\
\hline Hypothermia $<35^{\circ} \mathrm{C}$ & 2 & 3.6 \\
\hline \multicolumn{3}{|l|}{$\begin{array}{l}\text { Total amount of blood products } \\
\text { infused }\end{array}$} \\
\hline Red blood cells (U/kg) & 14 & $0.14(0.12-0.29)$ \\
\hline Plasma (mL/kg) & 14 & $20.00(11.76-35.71)$ \\
\hline Platelets (U/kg) & 4 & $0.70(0.17-1.22)$ \\
\hline Fibrinogen (U/kg) & 6 & $0.08(0.03-0.33)$ \\
\hline Prothrombin complex (U/kg) & 8 & $15.97(13.57-33.13)$ \\
\hline
\end{tabular}

ICU, Intensive Care Unit; U, unit; mL, milliliters; kg, kilogram. geographic regions in China mainland. A total of 39 hospitals in 19 provinces in China mainland contributed to the 1-day point prevalence survey of serious unintentional injury in children aged $0-16$ years. A total of 56 pediatric patients were identified to be suffered from unintentional injury, accounting for $5.5 \%(56 / 1,017)$ of all the ICU patients on the study day.

In our cohort, the first cause of unintentional injury was fall, followed by transportation injury, suffocation, poisoning, burns and drowning. It was reported that in China, drowning, traffic accidents, unintentional suffocation, poisoning and falls were the five main causes of injury death for children aged 1-4 years (8). We found falls were the first cause of injuries among children, which are similar to previous research $(9,10)$. Unlike adults, pediatric fall injury is more often because of an accident, other than suicide. Traffic accidents in developed countries are the leading cause of accidental death among children aged 0-14 years, followed by drowning (11). China's motor vehicle production has grown rapidly since the early 1990s (12), it is therefore not surprising that the proportion of deaths and morbidity related to traffic injuries is increasing (13). The higher traffic-related mortality may be related to the fact that Chinese children use less safety seats and seat belts (14). It is very common for mothers to hold babies in the position of the co-driver. Damage caused by airbag impact is commonly seen. It is an important time to urge the government to legislate for children to use seatbelts and child restraints in vehicles (15).

Other causes of serious unintentional injuries in our study included poisoning, suffocation, drowning, and burns. These injuries had obvious regional characteristics, and the incidence rate of children living in rural or urbanrural fringe area was significantly higher than that of children living in cities. This is different from other studies which showed that the accidental injury to children is a common phenomenon caused by child abuse and ignorance (16). Childhood injury data can be used to develop appropriate intervention strategies. Effective prevention guidance depends on detailed injury data that can show how risk changes as children grow. Drowning represents the leading cause of deaths caused by unintentional injuries among children between 1 and 4 years of age in the other investigation reports $(8,17)$. In addition, children who survive drowning may present severe long-term disabilities. Differences from other studies, there 
Table 4 The severity of disease score on survey day in children with serious unintentional injury compared with those on their ICU admission

\begin{tabular}{lcccc}
\hline Score & On ICU admission & On survey day & Z & P value \\
\hline PRISM III & $6.0(2.0-12.0)$ & $3.0(0.0-7.5)$ & -4.63 & $<0.001^{*}$ \\
GCS & $13.0(7.0-15.0)$ & $15.0(10.0-15.0)$ & -4.06 & $<0.001^{*}$ \\
PTS & $7.5(5.0-9.0)$ & $9.0(7.0-10.0)$ & -3.94 & $<0.001^{*}$ \\
\hline
\end{tabular}

*, P values indicate the significance of difference between data on survey day and on ICU admission. PRISM III, Pediatric Risk of Mortality

III; GCS, The Glasgow Coma Scale; PTS, Pediatric Trauma Score; ICU, Intensive Care Unit.

are only 3 cases of drowning children in our study, which may be related to the winter season of our investigation.

This study shows that the main cause of injury is age related. Previous studies have shown that in children younger than 15 years old, drowning and traffic-related injuries account for $54 \%$ and $16 \%$ of all injury deaths respectively (13). We found most patients who suffered from serious unintentional injuries in this study had an age of less than 6 years old $(n=42,75 \%)$. The leading causes of unintentional injury in infants and preschool children were falls, suffocation and transportation. In our survey, suffocation accounted for $16.1 \%$ and only occurred in children under six years old. Suffocation is the leading cause of unintentional injury death among infants under 1 year of age in most countries $(18,19)$. Babies with unintentional suffocation is mostly being covered by quilts, mothers turning over and accidentally crushing to death, blockage of mothers' nipples and foreign bodies in the trachea. These injury deaths, often resulting from hazards within the sleep environment, are preventable. The diversity of causes of injury shows that the toddlers and preschoolers' children are vulnerable. Because non-verbal and dependent on caregivers to meet their need, infants are at increased risk of suffocation, falls and burns. Young children with curiosity, exploring behaviors, and hand-to-mouth activities often have motor skills to approach dangerous situations, but lack the perception and cognitive ability to avoid injuries. Injuryrelated child development characteristics should therefore be the focus of expected guidance and should be considered in all injury prevention activities.

According the latest demographic statistics in China (2021.05), the male to female ratio for children under 16 years is about 114 . Our research shows that boys have 2.29 times more accidental injuries than girls $(\mathrm{P}<0.01)$. This ratio is higher than the gender ratio of the same age. The most common cause of injury in boys was fall injury, whereas in girls the common cause was traffic-related injury. Except for traffic-related injuries in our cohort, boys have a higher tendency to harm in all ages than girls. These findings are consistent with other pediatric studies (9,20-22). Boys are a dangerous group of children for accidental injury, because boys are more active than girls, are more curious about their surroundings, and have more dangerous behaviors. Gender differences in child injuries exist in most countries and increase with age. However, the pattern of injury was different in children from in adults. The most common injury mechanism among male adults is a motor vehicle accident, while most female adults are victims of falls and pedestrian accidents (23).

Accidental injuries to children are often related to economic, culture, habits and living conditions. Previous research shows obvious regional and demographic characteristics (24). We studied the differences in the types and causes of accidental injuries among children in urban and rural areas. We found that the geographical difference in the proportion of unintentional injuries among children with urban and rural residence was not significant. With the economic development in China, the gap between urban and rural areas has narrowed. Another reason may be that critically ill patients in rural areas may have died on the site if they do not have the opportunity to be sent to a high degree hospital. According to another report, left-behind children (who remain in rural regions of China while their parents leave to work in urban areas, these children are taken care of by their extended families, usually by grandparents or family friends) have a significantly higher risk of injury than children in urban areas, leading to a significantly increased risk of injury (25).

We also analyzed the onset time of unintentional injuries, and found that the injury happened on 12:00 18:00 PM in 27 cases (48.2\%), and 28 patients (50\%) had injuries happened at working day. This means that lack of supervision is the main cause of accidents. Studies have shown that lack of regulation, insufficient safety standards for home furniture and items, limited access to safe play areas, and uneven walking surfaces are risk factors for 
childhood fall in developing countries (26). More researches are needed to better understand the context of trauma and injury to children in low- and middle-income countries (27).

These 56 children suffered from a total of 106 lesions corresponding to 1.89 lesions per patient. The majority of lesions were to the thorax, head, abdomen and extremities. Most reports show head and neck and limbs as the most commonly injured body regions in adults (28). Many children had injury-related major complications. Respiratory failure was most seen, followed by shock, metabolic acidosis, and acute traumatic coagulopathy. Studies have reported that complications such as massive transfusion, invasive ventilation, and an initial GCS $\leq 8$ had a significant impact on ICU length of stay (29). After effective treatment during their ICU stay in our study, 45 (80.4\%) patients showed improvement, with GCS, PTS and PRISM III score significantly better than those before treatment. There were no deaths in our cohort during the study.

In our survey, although 35 patients received primary treatment at local hospitals, 35 patients $(62.5 \%)$ also needed resuscitation in the emergency department, 15 patients (26.8\%) still needed resuscitation in ICU in participating hospitals. This suggests that local hospitals have limited resources for children with unintentional injuries and there is a great risk in the process of transport. In China, there is a bias in the allocation of medical resources, and most doctors and medical institutions are located in large cities. There is a mismatch between the doctor distribution and the incidence of injuries, which are similar to the other developing countries (30). A study in Iraq shows that not only medical staff training is a long-term project, but short-term training of first-aid staff also has a significant impact on mortality in rural areas (31). Several papers on the improvement of pre-hospital and in-hospital care emphasize the need for a systematic approach based on a careful assessment of need (32). There is an urgent need for China to strengthen its survival chain, take precautionary measures, and prepare its medical system to meet this challenge. Injury prevention efforts should specifically target higher injury rates in children less than 6 years of age. Training primary medical staff first aid knowledge is also one of the urgent tasks. Research on accidental injury surveillance systems may provide more opportunities for injury and assessment of preventive measures.

\section{Limitation}

This is a national, multicenter, observational 1-day point prevalence study with most high degree children's hospitals in China involved. This study has several limitations. Due to the relatively small number of serious unintentional injuries, injury comparisons between different age/gender/ type of injury groups may have lower testing power. In this study, the seasonal factors of injury were not reflected. The investigation date is winter, and different seasons may cause different types of injuries.

Despite its limitations, this study can serve as an important reference for further research in children. These findings still apply and can inform the development of China's future safe living environment and the development of interventions to reduce the incidence of injuries.

\section{Conclusions}

Childhood unintentional injuries represent a major public health problem in China. Higher injury rates among children under 6 years old of age illustrate the need for preventive measures, especially programs and public policies targeting this high-risk group. This study may also provide a primitive framework to build and develop a national unintentional injury surveillance system as a major step in benchmarking actions taken.

\section{Acknowledgments}

The authors are grateful to all pediatrician contactors of 39 participating hospitals (Appendix 1). We also thank to Mr. Yikan Sun, Faculty of Medicine, University of New South Wales, Australia for helpful comments on the article and for his editorial support.

Funding: This work was supported by the grants from the Key Program of The Independent Design Project of National Clinical Research Center for Child Health. [No. G20B0009 (Linhua Tan)].

\section{Footnote}

Reporting Checklist: The authors have completed the STROBE reporting checklist. Available at https:// tp.amegroups.com/article/view/10.21037/tp-21-387/rc

Data Sharing Statement: Available at https://tp.amegroups. com/article/view/10.21037/tp-21-387/dss

Conflicts of Interest: All authors have completed the ICMJE uniform disclosure form (available at https://tp.amegroups. 
com/article/view/10.21037/tp-21-387/coif). The authors have no conflicts of interest to declare.

Ethical Statement: The authors are accountable for all aspects of the work in ensuring that questions related to the accuracy or integrity of any part of the work are appropriately investigated and resolved. This study was conducted in accordance with the Declaration of Helsinki (as revised in 2013). The study was approved by The Ethics Committee of The Children's Hospital, Zhejiang University School of Medicine (No. 2017-IRB-042). This was an observational study with minimal risk and no informed consent required.

Open Access Statement: This is an Open Access article distributed in accordance with the Creative Commons Attribution-NonCommercial-NoDerivs 4.0 International License (CC BY-NC-ND 4.0), which permits the noncommercial replication and distribution of the article with the strict proviso that no changes or edits are made and the original work is properly cited (including links to both the formal publication through the relevant DOI and the license). See: https://creativecommons.org/licenses/by-nc-nd/4.0/.

\section{References}

1. Sminkey L. World report on child injury prevention. Inj Prev 2008;14:69.

2. Jiang $X$, Zhang $Y$, Wang $Y$, et al. An analysis of 6215 hospitalized unintentional injuries among children aged 0-14 in northwest China. Accid Anal Prev 2010;42:320-6.

3. Hyder AA, Sugerman DE, Puvanachandra P, et al. Global childhood unintentional injury surveillance in four cities in developing countries: a pilot study. Bull World Health Organ 2009;87:345-52.

4. Pike I, Piedt S, Warda L, et al. Developing injury indicators for Canadian children and youth: a modifiedDelphi approach. Inj Prev 2010;16:154-60.

5. Haagsma JA, Graetz N, Bolliger I, et al. The global burden of injury: incidence, mortality, disability-adjusted life years and time trends from the Global Burden of Disease study 2013. Inj Prev 2016;22:3-18.

6. Fang Y, Dai L, Jaung MS, et al. Child drowning deaths in Xiamen city and suburbs, People's Republic of China, 2001 5. Inj Prev 2007;13:339-43.

7. Cao H, Wang J, Li Y, et al. Trend analysis of mortality rates and causes of death in children under 5 years old in Beijing, China from 1992 to 2015 and forecast of mortality into the future: an entire population-based epidemiological study. BMJ Open 2017;7:e015941.

8. Wang Y, He C, Li X, et al. Nationwide study of injuryrelated deaths among children aged 1-4 years in China, 2000-2008. J Paediatr Child Health 2014;50:E94-E101.

9. Mack KA, Rudd RA, Mickalide AD, et al. Fatal unintentional injuries in the home in the U.S., 2000-2008. Am J Prev Med 2013;44:239-46.

10. Qiu X, Wacharasin C, Deoisres W, et al. Characteristics and predictors of home injury hazards among toddlers in Wenzhou, China: a community-based cross-sectional study. BMC Public Health 2014;14:638.

11. Nyári TA, McNally R. Seasonal variation in childhood mortality. J Matern Fetal Neonatal Med 2020;33:4055-61.

12. Zhou Y, Baker TD, Rao K, et al. Productivity losses from injury in China. Inj Prev 2003;9:124-7.

13. Wang SY, Li YH, Chi GB, et al. Injury-related fatalities in China: an under-recognised public-health problem. Lancet 2008;372:1765-73.

14. Chen X, Yang J, Peek-Asa C, et al. Parents' knowledge, attitude, and use of child restraints, Shantou, China. Am J Prev Med 2014;46:85-8.

15. Jiang B, Liang S, Peng ZR, et al. Transport and public health in China: the road to a healthy future. Lancet 2017;390:1781-91.

16. Rivara FP. Prevention of death and disability from injuries to children and adolescents. Int J Inj Contr Saf Promot 2012;19:226-30.

17. Jullien S. Prevention of unintentional injuries in children under five years. BMC Pediatr 2021;21:311.

18. Yao X, Skinner R, McFaull S, et al. At-a-glance - 2015 injury deaths in Canada. Health Promot Chronic Dis Prev Can 2019;39:225-31.

19. Kong F, Wang A, He J, et al. Trend of unintentional suffocation death for infants under 1 year of age from 2009 to 2018 in Hunan, China: a cross-sectional study. BMJ Open 2020;10:e038666.

20. Zhang H, Li Y, Cui Y, et al. Unintentional childhood injury: a controlled comparison of behavioral characteristics. BMC Pediatr 2016;16:21.

21. Mattila V, Parkkari J, Kannus P, et al. Occurrence and risk factors of unintentional injuries among 12- to 18-yearold Finns--a survey of 8219 adolescents. Eur J Epidemiol 2004;19:437-44.

22. Ma J, Guo X, Xu A, et al. Epidemiological analysis of injury in Shandong Province, China. BMC Public Health 2008;8:122.

23. Bolandparvaz S, Yadollahi M, Abbasi HR, et al. Injury 
patterns among various age and gender groups of trauma patients in southern Iran: A cross-sectional study. Medicine (Baltimore) 2017;96:e7812.

24. Jung JH, Kim DK, Jang HY, et al. Epidemiology and Regional Distribution of Pediatric Unintentional Emergency Injury in Korea from 2010 to 2011. J Korean Med Sci 2015;30:1625-30.

25. Yang L, Nong QQ, Li CL, et al. Risk factors for childhood drowning in rural regions of a developing country: a casecontrol study. Inj Prev 2007;13:178-82.

26. de Sousa Petersburgo D, Keyes CE, Wright DW, et al. The epidemiology of childhood injury in Maputo, Mozambique. Int J Emerg Med 2010;3:157-63.

27. Hofman K, Primack A, Keusch G, et al. Addressing the growing burden of trauma and injury in low- and middleincome countries. Am J Public Health 2005;95:13-7.

Cite this article as: Ye J, Bao Y, Zheng J, Liang J, Hu L, Tan L; on behalf of the Pediatric Intensive Care Committee of Chinese Medical Doctor Association Investigators. Epidemiology of unintentional injury in children admitted to ICU in China mainland: a multi-center cross-sectional study. Transl Pediatr 2022;11(3):340-348. doi: 10.21037/tp-21-387
28. Eftekhar B, Zarei MR, Ghodsi M, et al. Comparing logistic models based on modified GCS motor component with other prognostic tools in prediction of mortality: results of study in 7226 trauma patients. Injury 2005;36:900-4.

29. Böhmer AB, Just KS, Lefering R, et al. Factors influencing lengths of stay in the intensive care unit for surviving trauma patients: a retrospective analysis of 30,157 cases. Crit Care 2014;18:R143.

30. Gwatkin DR, Bhuiya A, Victora CG. Making health systems more equitable. Lancet 2004;364:1273-80.

31. Murad MK, Husum H. Trained lay first responders reduce trauma mortality: a controlled study of rural trauma in Iraq. Prehosp Disaster Med 2010;25:533-9.

32. Mock C, Quansah R, Krishnan R, et al. Strengthening the prevention and care of injuries worldwide. Lancet 2004;363:2172-9. 
Appendix 1 List of the participating investigators on epidemiology of serious unintentional injury in children in China from Pediatric Intensive Care Committee of Chinese Medical Doctor Association

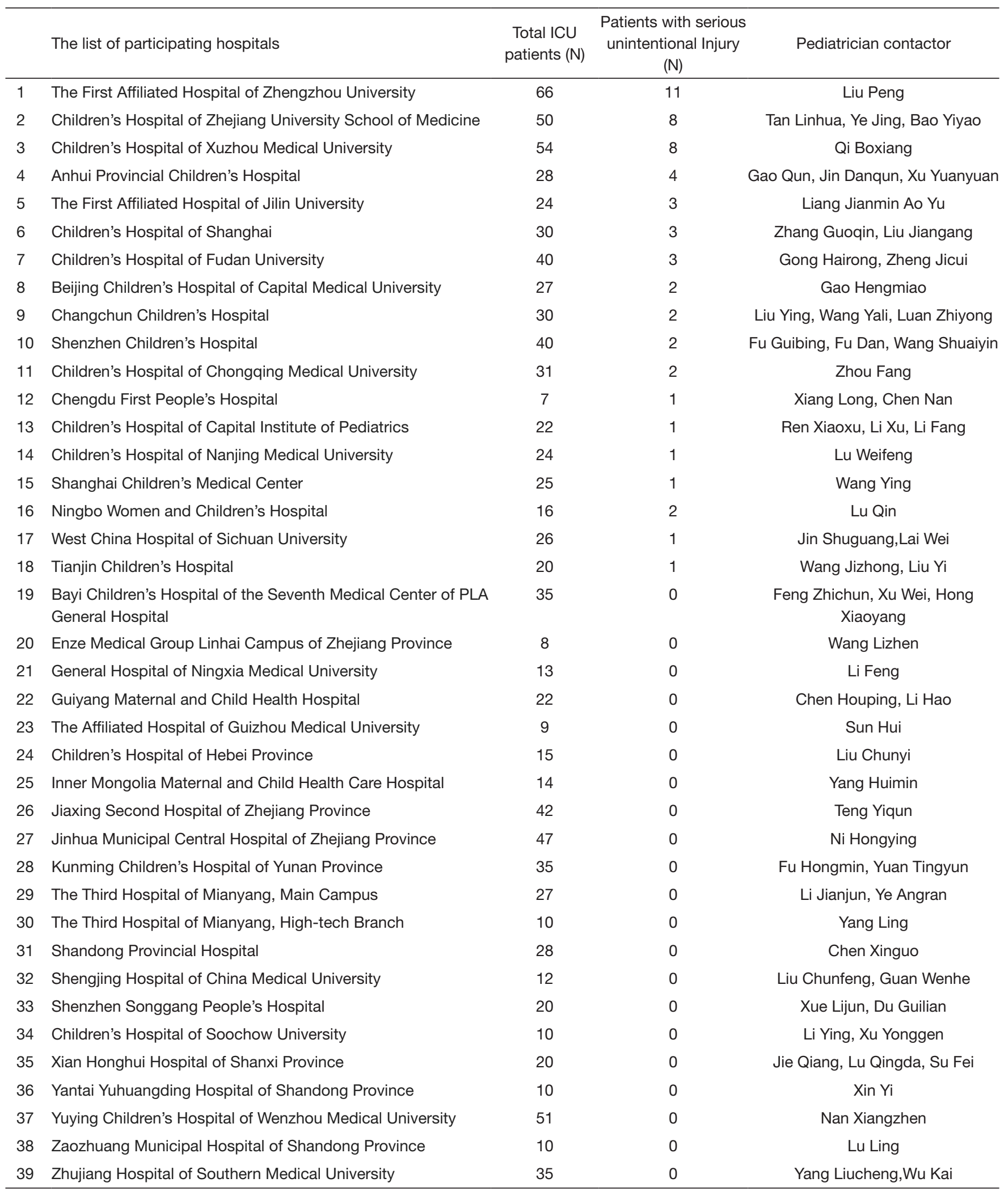

